\title{
A Study on User Experience Factors of Public Kiosk
}

\author{
Seung-Min Lee \\ Department of Multimedia, Namseoul University \\ mini0920@nsu.ac.kr
}

\begin{abstract}
The purpose of this study is to propose digital contents direction of public service design by deriving the kiosk user experience (UX) factor in public place.

In order to elicit the user experience factors of kiosk in the public place, the criteria of derivation of the factor by arranging the data on-line and off-line was prepared. Based on this criterion, the questionnaire was conducted to finally extract the user experience factors of the kiosk in public places.

29 kiosk UX items were created such as usability, reliability, sustainable value offer, usefulness, superiority of information quality, convenience, economics, logicality of information structure, expectation, uniqueness, amusement, interest, novelty, newness, harmony with environment, charming, concsistency, attractiveness, openess, popularity, security of information, suitability, stability, distinction, interaction, aesthetic, diversity, approach possibility and adaptability. In addition, 29 user experience items finally converged to four factors: practicality, emotion, popularity, and aesthetics.

The results of this study can reduce the various types of trial and error that can occur during the planning of new information technology. In addition, I hope that it can be used as a useful framework in terms of academic and practical aspects in support of the expansion of multimedia kiosk market.
\end{abstract}

Keywords: User Experience, Kiosk, Affective Design, Public Contents

\section{Introduction}

In a recent design field, the ultimate objective has been to create user experience(UX). The existing design has changed into the one with emotions and experiences that is produced among users, products and service beyond the physical meaning which is limited to the original forms, functions and materials. In addition, it has been changing in the direction of leading user's experience rather than physical forms. Especially it is very critical for kiosk to attract people in consideration of individual's features because kiosk is going to be used by unspecified majority of people after located in public spaces.

Since the users of kiosk are offered data and the information that they want through screen, at this time whether and how convenient users can navigate relies on contents including interface rather than hardware. Multimedia interface with graphic, video, sound and text is based on user experience, and has developed while reflecting users' requirement as much as possible.

Today, kiosk is one element consisting of data, which makes it easier for users to access by using a motion graphic's advantage. It not only shows static information screen but also leads user's access by expressing informational images with motion graphic. These technology providing interactive contents creates a space for users to get various information in and also plays a role in helping users participate voluntarily via new experiences.

Received (November 8, 2017), Review Result (January 19, 2018), Accepted (January 22, 2018) 
The main users of kiosk would be determined according to the purpose of installation. Because users in public places are different in age, gender, job, the standard of living and region, kiosk contents design should reflect their own differences and features. Furthermore, digital contents in public spaces could deliver the informational messages with visual image and realistic expression through empirical factors for inducing the participation of users and provision of information in accordance with the traits of locations.

Therefore, kiosk needs to be produced to cause interests and meet user's needs, and the relevant customer satisfactions are also getting important. kiosk has to present a good image as well as user's satisfactions by providing better experiences to customers.

However, the previous studies relative to user experience were mainly based on web, web \& software and mobile devices, so on basis of personal media it could hardly apply to kiosk for public uses because those subjects' features.

The purpose of this study was to set an integrated evaluation index via kiosk user experience factors in public locations, and to propose the direction of digital contents in public service design.

\section{Method}

This study examined the preceding researches in many different fields about factors organizing user experience in order to draw kiosk UX factors, as shown in Figure 1. We also analyzed big data in social medias by using 'SOCIAL metrics' solution from Daum soft company. 'SOCIAL metrics' is the solution applied by one of data analysis techniques, opinion mining, which is an efficient way to obtain sufficient data and insight for finding out patterns for fast-changing users' needs. Lastly, we interviewed some experts in UX, and collected opinions regarding things to be considered for kiosk UX.

We established standards for drawing factors based on data of online and offline to acquire UX factors of kiosk in public spaces. We conducted a survey on basis of the standards and extracted those factors.

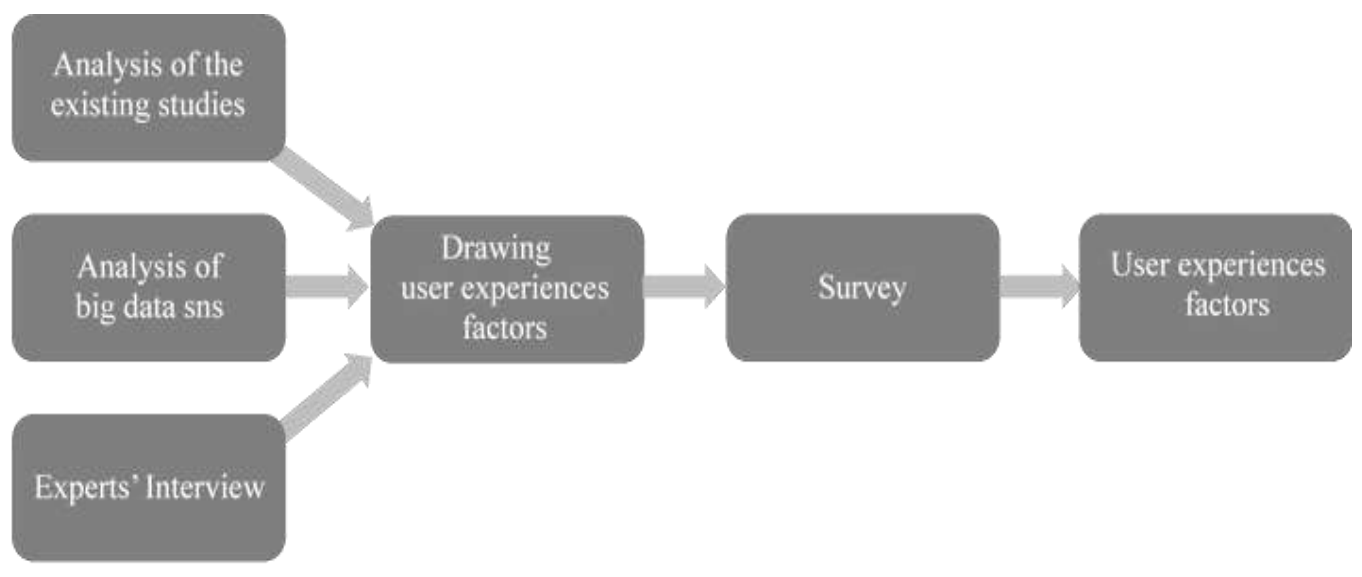

Figure 1. Procedure to Extract UX Factors of Kiosk

\section{Theoretical Discussion}

\subsection{Kiosk as Public Service}

The authorities lately has made a number of efforts to build ubiquitous city and smart city based on IT. It has shown that information media by digital media kiosk including complicated interaction with several functions such as complex and various traffic information and life information of city, weather and personal media application has been remarkably increasing. 
kiosk used at several spaces with various purposes was introduced at "Daejeon International Expo" in 1993, since then multimedia-using kiosk now can be seen in many different places after going though much progress.

kiosk is delivering the necessary information according to the spaces that they are located in and now is trying to expand its range of use, via differentiated information as well as charging for information[1]. Multimedia-type of kiosk interacts with users in a more sophisticated way, and brings entertainment and curiosity rather than pursuing usability only. As focusing on users' convenience using text with graphic, movie and sound, it has developed by reflecting users' requirement as much as possible based on UX[2]. Now kiosk has been located in public spaces such as streets, shopping malls, movie theaters, airports, conference halls and hotels and has provided information through joy and new experiences. In addition, Daum installed 'Digital View' offering maps and news in every subway station of line 1 to line 4 in cooperation with Seoul Metro and Finger Touch. Local government is utilizing kiosk with touch screen in order to realize routes, as shown in Figure 2, transit routes and establishing bus information system with map search as well as public transportation information. The provided information from kiosk for giving users information and cultural experiences may differ depending on each environment. This is because different kind of spaces make different expected information. Namely, the information differs by the features of spaces(characteristics, roles, functions and etc.), then the relevant contents should be composed differently.

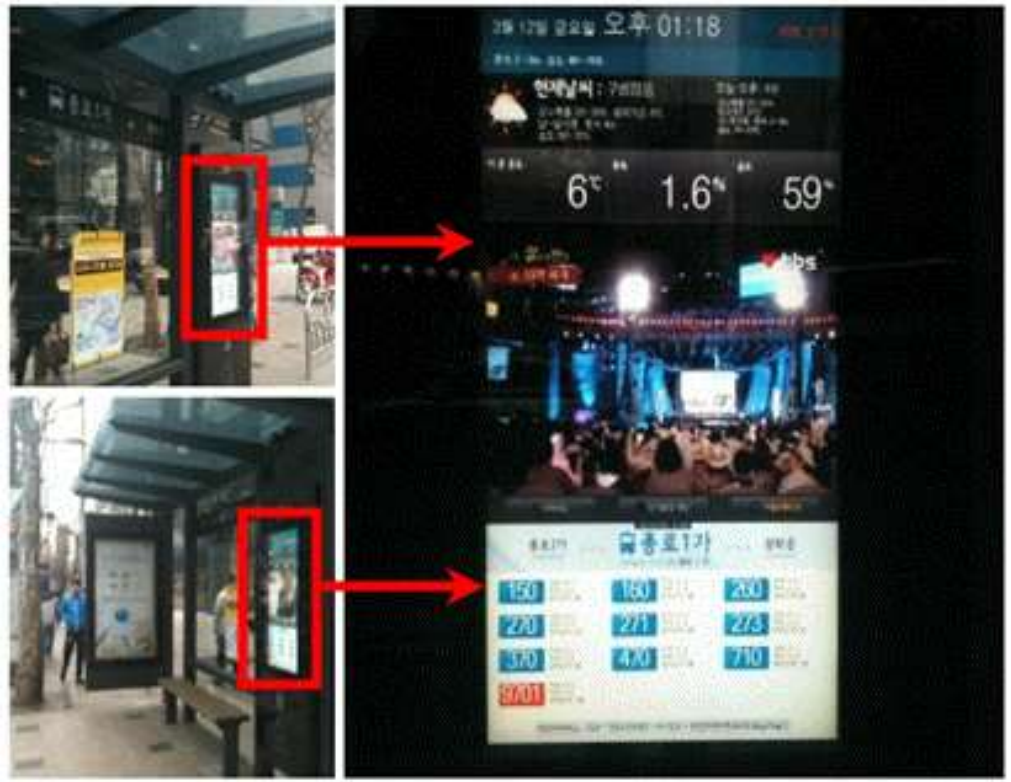

Figure 2. Case of Kiosk in Bus Stops

Digital contents in public spaces should be produced to deliver visual images and information messages with realistic expressions by offering information for each space and experience design for leading participations.

They should create contents which can present the empirical interactions to let users recognize those messages by participation in person.

So far, kiosk as a public service has given users a variety of multimedia contents via display screen, but now it is explored for different ways of convergence rather than simply offering information. The convergence is for interactive communications to attract the interest and joining.

The kiosk as a two-way communication channel has expanded its role in from just offering information to providing various contents which promote leisure and cultural life, 
thereby the availability of kiosk has been increased. Therefore, kiosk needs to be produced to cause interests and meet user's needs, and the relevant customer satisfactions are also getting important. kiosk has to present a good image as well as user's satisfactions by providing better experiences to customers.

However, for now there were just few fundamental researches for figuring out kiosk's $\mathrm{UX}$ and most of all remains case investigation of kiosk and application and utilization of contents. So it is required to study kiosk users' empirical factors to evaluate kiosk as a public facility and set the direction and standards for production.

\subsection{Concept of user Experiences(ux) and its Factor}

According to Wikipedia, UX is the meaning used in user computer interaction study, and many of UX principle is still used in the development of software and hardware in computer science field. However, this concept is now applied to industrial service, products, process, society, culture as well as computer.

UX was mentioned from "User Experience With the Cyber Graphics Terminal" of Edwards and Kasik(1974), at the first time, afterward the relevant studies has continued as mainly trying to make positive empirical values through mutual consensus between human and machine in a context of Human Centered Design[3].

Donald Norman(1988) said that human being has a certain behavior with some purpose, and when users use the information system, their behavior is followed by interaction among the purpose of using a system, the information system itself and a cognitive attribute in order to trigger users' behavior. The meaning of 'User Experience' is including the overall experiences that users can gain during use of the system while 'User interface' that originally has been studied in HCI or design is a term focusing on the interface between human and the system[4].

UX's meaning could be slightly different due to academic backgrounds or viewpoints. Dewey mentioned that the experience was the entire process for people to adapt the environment as one big organism and the result from the interplay between all living things and certain conditions of their living world. Also he explained that it was a result or a signal or a present from interaction between an organism and the environment which transformed the interaction into a participation and a communication when that interaction could be performed completely. Further this experience could be regarded as a perfect one such as art works when compositional, sensual, emotional, spatio-temporal threads would be balanced. As a result, Dewey suggested that the complete experience was the steady movement for problem solving or satisfaction, plus this only experience should end up with the perfect harmony between humans and objects.

So UX could be explained that user's participation formed a link with objects directly and entirely. Also it was to offer users the environment putting a differentiated value in order that users could experience the experiences-based products, that was to give the environment which was helpful for users to experience rather than just using products. This environment was going to make the frame to understand user environment as 'experience' visually, which provided refreshed and improved 'experience' by approach of 'needs', and the derived experience could be developed by restructuring another[5].

On the other hand, McMullin(2003) said that user experience could not be realized at once, but could be acquired through series of process connected with expectation, proximity, awareness, connection, action, response and evaluation. At this time, experience of process and expectation would be compared by users, if they regarded their experience as a positive one, then users went back into the cycle of experience and kept doing it. As this was the analysis about behavior of using or buying products or service consistently, it implied that the attribute of experience within all process of UX should be understood for getting success through UX[6]. 
Whereas UX factors for the optimum experience vary. If you look at the opinion of academics who studied those factors, the factors can be picked out as usefulness, usability and affect.

Specifically, the claim of scholars who studied UX factors was the following. First, UX factors were defined as perceptions, emotion, attitudes, thoughts and behavior in the study of Russell[7].

Peter Morville(2006) suggested that the traits of UX design are useful, usable, desirable, findable, accessible, credible and valuable, which can also be used as a major elements for scale analysis of UX recently[8].

Mikahiltunen, Markku Laukka, JariLuomala(2002) proposed 5 different types of UX factors. The relationship among factors could be expressed as multiplication ( $\mathrm{UX}=$ utility $\mathrm{X}$ usability $\mathrm{X}$ availability $\mathrm{X}$ aesthetic $\mathrm{X}$ offline issue), and each elements could not complement each other perfectly. First, utility indicates "recognizing the provided service as the worthy." Being aware of the value about utility of service could make UX much practical and valuable. Second, usability as already defined in a various way was said as "usability means ease of use that presents that it is easy for users to learn how to manage, how to input and to read output of factors" by Institute of Elecrical and Electronics Engineering. Third, availability defined the fundamental element about whether or not service can be provided when uses want. This factor was as important as service's stability, so if users couldn't operate digital devices whenever they want, it could be very negative on UX. Fourth, aesthetics induced user's interest by service's form or impression, which could be a first attraction to let people get interested in products. Aesthetic parts of products and internet service could spark an interest and affect the way we experience. In addition, it could determine the entire impressions or images about the goods. Fifth, offline issue had company brand, back-end process and trustworthiness as major influencing factors, and this includes brand or supporting business process[9].

UX framework of Hassensahl(2006) had two different attributes, product-oriented aspect and people-oriented aspect. In product-oriented aspect, he discussed the shapes of experience such as manipulation in a practical way, stimulation in a pleasurable way, identification and evocation. In people-oriented aspect, experience appeared as appeal, pleasure and satisfaction. However he insisted that the user's expectation in mind was important the most, because those results could be totally different if users stayed at task-based goal mode or entertainment-based behavior mode[10].

According to study of Kaisa et al., (2009), academic area had Hedonic aspect, Co-experience and Dynamic of experience about UX, while business area approached on user experience by Functionality, Usability and Novelty. There were the gap between two areas, so they presented the necessity of an effective UX evaluation method that embraced two different accesses[11].

Therefore, this study pursued to bring up the diverse and comprehensive UX factors that had an effect on user's behavior pattern. In other words, we tried to get empirical factors which reflected from the macroscopic environment around users to a specific situation and indivisual's mind. 


\section{Results}

\subsection{Collecting ux Factors}

This study looked through the preceding studies relative to user experience in information system, digital media and HCI field to make up the questions for kiosk UX factors. On the basis of this existing research, we extracted 20 questions which is possible to check UX factors with kiosk's attributes. This followed the below Table 1.

Table 1. Kiosk UX Factors Questions via the Preceding Research

\begin{tabular}{|l|l|}
\hline \multirow{3}{*}{ usability } & $\begin{array}{l}\text { Frank Guo(2012), Peter Moville(2004), Choi \& Park(2012), Sung, } \\
\text { Woo \& Ko(2007), Davis(1989), Park(2009), Choi(2000), } \\
\text { Jang(2008), Liu \& Kim(2013) }\end{array}$ \\
\hline value & Frank Guo(2012), Peter Moville(2004) \\
\hline adoptability & Frank Guo(2012) \\
\hline desirability & Frank Guo(2012), Peter Moville(2004) \\
\hline useful & $\begin{array}{l}\text { Peter Moville(2004), Venkatesh \& Davis(2000), Jang(2008), } \\
\text { Noh(2011), Taylor\& Todd(1995), Liu \& Kim(2013) }\end{array}$ \\
\hline findable & Peter Moville(2004) \\
\hline accessible & Peter Moville(2004), Choi \& Park(2012), Sung, Woo \& Ko(2007) \\
\hline credible & Peter Moville(2004) \\
\hline $\begin{array}{l}\text { information } \\
\text { quality }\end{array}$ & Park(2008) \\
\hline security & Park(2008) \\
\hline environmental & Choi \& Park(2012), Sung, Woo \& Ko(2007) \\
\hline concsistency & Choo \& Choi(2007) \\
\hline economics & Choo \& Choi(2007) \\
\hline stability & Choo \& Choi(2007) \\
\hline aesthetic & Choo \& Choi(2007), Mika Hiltunen(2007) \\
\hline simplicity & Choo \& Choi(2007) \\
\hline interaction & Choo \& Choi(2007), Oh(2008) \\
\hline expectation & Won(2011) \\
\hline convenience & Won(2011) \\
\hline necessity & Won(2011) \\
\hline
\end{tabular}

We also analyzed big data in social medias, using 'SOCIAL metrics' solution from Daum soft company applied by one of data analysis techniques, opinion mining. 'SOCIAL metrics' gives a map of related terms regarding exposure frequency in social media where users put some key words and offers the most diffused tweet messages about key words by positive/negative reactions and weather. 'SOCIAL metrics' is useful to check the issues and the air toward the key words on social media.

Hence this study organized kiosk UX factors items by utilizing the key words of kiosk, a guide system and an unmanned information system, which are considered as the words looked up the most frequently about kiosk. Look at Table 2 . 


\section{Table 2. Kiosk UX Factors Questions via SOCIAL Metrics's Sensitive Keywords}

\begin{tabular}{|l|l|}
\hline \multicolumn{1}{|c|}{ sensitive keywords } & diversity \\
\cline { 1 - 2 } various & $\begin{array}{l}\text { clarity } \\
\text { logicality } \\
\text { orderly } \\
\text { consistency } \\
\text { integrity }\end{array}$ \\
\hline new & newness \\
\hline enjoy & $\begin{array}{l}\text { interestingness } \\
\text { entertainingness }\end{array}$ \\
\hline interesting & differentiation \\
\hline good & popular \\
\hline unusual & aesthetic \\
\hline famous & usefulness \\
\hline refine & necessity \\
\hline help up & interaction \\
\hline need & $\begin{array}{l}\text { stability } \\
\text { security } \\
\text { reliability }\end{array}$ \\
\hline affect & durability \\
\hline safe & efficiency \\
\hline constantly & \\
\hline efficient & \\
\hline
\end{tabular}

Lastly, we did some interviews to experts in UX field(1 university faculty, 1 designer) and collected the opinion about a number of measurement standards considered significantly for kiosk UX. Thus the following items of Table 3 containing features as a pubic facility should be added to kiosk UX items.

\section{Table 3. Kiosk UX Factors Questions via Expert Interview}

\begin{tabular}{|l|}
\hline Attraction to catch pedestrian's eyes \\
\hline Balance with surrounding environment \\
\hline Openness for unspecified majority of people \\
\hline Differentiated design well represented about the image of installation spaces \\
\hline Installation at places where visitors need to get information \\
\hline
\end{tabular}

So, we rearranged the measurement questions after discussing the integrated evaluation direction. In doing so, we could notice the limitation of kiosk UX factors questions and secure reliability.

We eventually came up with 20 items from the preceding research of Table 1 and 15 items using opinion mining of Table 2, but factors which had overlapped or similar ideas in UK factors questions via expert interview would be combined. As a result of that, we had 30 items at last like Table 4. 
Table 4. Mean Value of Kiosk UX Factors Questions( $N=138)$

\begin{tabular}{|c|c|c|}
\hline survey number & questions & mean \\
\hline 1 & usability & 3.57 \\
\hline 2 & sustainable value offer & 3.41 \\
\hline 3 & efficiency & 2.99 \\
\hline 4 & charming & 3.54 \\
\hline 5 & usefulness & 3.59 \\
\hline 6 & approach possibility & 3.65 \\
\hline 7 & reliability & 3.49 \\
\hline 8 & superiority of information quality & 3.47 \\
\hline 9 & security of information & 3.28 \\
\hline 10 & concsistency & 3.45 \\
\hline 11 & economics & 3.57 \\
\hline 12 & stability & 3.30 \\
\hline 13 & aesthetic & 3.20 \\
\hline 14 & interaction & 3.22 \\
\hline 15 & expectation & 3.28 \\
\hline 16 & convenience & 3.68 \\
\hline 17 & diversity & 3.39 \\
\hline 18 & logicality of information structure & 3.36 \\
\hline 19 & newness & 3.37 \\
\hline 20 & novelty & 3.52 \\
\hline 21 & amusement & 3.38 \\
\hline 22 & uniqueness & 3.33 \\
\hline 23 & popularity & 3.47 \\
\hline 24 & adaptability & 3.54 \\
\hline 25 & interest & 3.42 \\
\hline 26 & harmony with environment & 3.31 \\
\hline 27 & openess & 3.72 \\
\hline 28 & distinction & 3.28 \\
\hline 29 & suitability & 3.59 \\
\hline 30 & attractiveness & 3.57 \\
\hline
\end{tabular}

\subsection{Result Extracting ux Factors}

The collected 30 items were consisted of survey questions and the hardly understandable sentences were modified to make it easier for participants. The survey was set by web system and 5 likert scale was used. Items with "a little" for more than 3 points were to be in kiosk UX factors items.

The target of survey was men and women in twenties who are familiar with digital media and total 138 of questions were collected.

The data from survey for extracting kiosk UX factors was processed in descriptive statistic and factor analysis by SPSS.

As shown at Table 4, total 29 items which recorded more than 3 points except 'efficiency' were extracted among 30 chosen UX factors measurement items. 'Efficiency' with average 2.99 points was not validated, so we determined that it was not adequate for kiosk UX factors and excluded it.

Afterward we conducted factor analysis for drawing kiosk UX factors, and consequently we got 5 types of factors as they were shown on Table 5 .

$62.26 \%$ of the entire variation was explained. When we judged that the items which represented over 0.3 of factor loadings were included in the relevant factors, we could tell that 30 kiosk UX factors were consist of 5 different types of factors. 
We looked through the reliability of items to find out the consistency and accuracy of items composing 5 different kiosk UX factors(Table 5).

The reliabilities of items composing factor 1 , factor 2 , factor 3 and factor 4 were 0.905 , $0.896,0.800$ and 0.826 respectively, and those were all over 0.7 of reliability coefficient critical. It meant that the items were reliable enough and in case of deleting items, there was no problem with the reliability coefficient.

However the reliability of items of factor 5 was 0.599 which was under 0.7 of reliability coefficient critical. It was excluded because of inappropriateness.

kiosk UX factors selected based on factor analysis and verification were respectively named as practicality, emotion, popularity and aesthetic, and each of meanings are the following table6.

Table 5. Factor Analysis of Kiosk UX

\begin{tabular}{|c|c|c|c|c|c|c|}
\hline questions & factor 1 & factor2 & factor3 & factor 4 & factor5 & $\begin{array}{c}\text { level of } \\
\text { confidence }\end{array}$ \\
\hline usability & .747 & .203 & .036 & .057 & .233 & \multirow{9}{*}{.905} \\
\hline reliability & .736 & .230 & .107 & .050 & .024 & \\
\hline $\begin{array}{l}\text { sustainable value } \\
\text { offer }\end{array}$ & .687 & .195 & .282 & .178 & .058 & \\
\hline usefulness & .666 & .140 & .389 & .161 & .121 & \\
\hline $\begin{array}{l}\text { superiority of } \\
\text { information } \\
\text { quality }\end{array}$ & .611 & .229 & .349 & .284 & .043 & \\
\hline convenience & .605 & .111 & .001 & .389 & .282 & \\
\hline economics & .545 & .324 & .038 & .332 & .282 & \\
\hline $\begin{array}{l}\text { logicality of } \\
\text { information } \\
\text { structure }\end{array}$ & .536 & .131 & .452 & .479 & -.031 & \\
\hline expectation & .499 & .363 & .189 & .398 & .140 & \\
\hline uniqueness & .234 & .793 & .116 & .212 & .070 & \multirow{7}{*}{.896} \\
\hline amusement & .311 & .789 & .016 & .167 & .027 & \\
\hline interest & .255 & .733 & .265 & .097 & .067 & \\
\hline novelty & .161 & .711 & .292 & .205 & .011 & \\
\hline newness & .168 & .695 & .203 & .277 & .165 & \\
\hline $\begin{array}{l}\text { harmony with } \\
\text { environment }\end{array}$ & .107 & .560 & .389 & .296 & .008 & \\
\hline charming & .328 & .417 & .376 & .269 & -.091 & \\
\hline concsistency & .345 & .188 & .686 & -.063 & -.187 & \multirow{6}{*}{.800} \\
\hline attractiveness & .070 & .341 & .629 & .298 & .200 & \\
\hline openess & .155 & .231 & .616 & .123 & .208 & \\
\hline popularity & .265 & .159 & .612 & .154 & .297 & \\
\hline $\begin{array}{l}\text { security of } \\
\text { information }\end{array}$ & -.016 & .140 & .545 & .199 & .235 & \\
\hline suitability & .315 & .097 & .498 & .461 & .026 & \\
\hline stability & .300 & .169 & .134 & .727 & .099 & .826 \\
\hline
\end{tabular}




\begin{tabular}{|c|c|c|c|c|c|c|c|}
\hline distinction & .096 & & .383 & .205 & 679 & .014 & \\
\hline interaction & .364 & & .287 & .082 & .607 & .046 & \\
\hline aesthetic & .022 & & .437 & .226 & .538 & -.064 & \\
\hline diversity & .185 & & .357 & .288 & .503 & .225 & \\
\hline $\begin{array}{l}\text { approach } \\
\text { possibility }\end{array}$ & .201 & & .051 & .241 & -.067 & .797 & .599 \\
\hline adaptability & .398 & & .055 & .205 & .322 & .577 & \\
\hline eigen value & 12.090 & & .095 & 1.565 & 1.238 & 1.068 & \\
\hline \multicolumn{7}{|c|}{ KMO(Kaiser-Meyer-Olkin) } & .907 \\
\hline \multirow{2}{*}{\multicolumn{3}{|c|}{ Test of bartlett of imprisonment }} & \multicolumn{3}{|c|}{$\begin{array}{r}\text { Chi-Square } \\
\end{array}$} & & 2334.206 \\
\hline & & & \multicolumn{3}{|c|}{ dff(p) } & & 406 \\
\hline
\end{tabular}

Table 6. User Experience Factors of Kiosk

\begin{tabular}{|l|l|}
\hline 1) Practicality & $\begin{array}{l}\text { It is easy and convenient for users to use kiosk. } \\
\text { It is about letting users feel that the offered service is valuable by } \\
\text { intuitionally understanding interface and contents. }\end{array}$ \\
\hline 2) Emotion & $\begin{array}{l}\text { This is emotional reaction experienced during using of kiosk. } \\
\text { It is about attracting user's interest by creative images and being in } \\
\text { harmony with surrounding environment. }\end{array}$ \\
\hline 3) Popularity & $\begin{array}{l}\text { In accordance with the space for kiosk and the context, this means } \\
\text { openness for unspecified majority of people, attraction to catch } \\
\text { pedestrian's eyes and security for complete the problem because of } \\
\text { open environment. }\end{array}$ \\
\hline 4) Aesthetic & $\begin{array}{l}\text { It gives friendliness by design for public spaces and distinctive } \\
\text { contents to reflect kiosk's physical and environmental features. }\end{array}$ \\
\hline
\end{tabular}

\section{Conclusion and Proposals}

Digital contents in public space should pursue satisfaction by providing proper information optimized for locations and by different empirical elements for making user's participation. It was the urgent issue to set the integrated evaluation index and the directions for contents of public service design with kiosk UX factors of public space.

The purpose of this study was to draw the factors relative to kiosk user experience because the situation that using kiosk has been generalized urges to assess the performance.

So we went through 3 steps, literature investigation, analysis on big data of social media and expert interviews, and came up with UX measurement index which can be applied to kiosk, and conducted statistical verification.

29 kiosk UX items were created such as usability, reliability, sustainable value offer, usefulness, superiority of information quality, convenience, economics, logicality of information structure, expectation, uniqueness, amusement, interest, novelty, newness, harmony with environment, charming, concsistency, attractiveness, openess, popularity, security of information, suitability, stability, distinction, interaction, aesthetic, diversity, approach possibility and adaptability.

In addition, final UX items converged on practicality, emotion, popularity and aesthetic.

Today the desire to get new experience, sensitive satisfaction and convenience of using information system cannot help but keep increasing because of the development of various digital media, which was demonstrated in this study as well. If you look at the key words extracted as UX items by analysis on big data of social media, the following 
emotional words held a dominant position: various, new, joy, good, distinctive, famous, sophisticated etc. Above all, the desire for the sensitive experience was pretty powerful. Those needs of users could be checked by accounted for $50 \%$ of the whole 4 factors with sensitive factors and aesthetic factors.

Function or cognitive factors linked with usage already became the basic complements due to upward leveling technical skills of the recent media. Otherwise, sensitive stimulation such as distinctive, amazing and joyful could be the factors appealing to users.

kiosk has different information in accordance with installation environment. In other words,

The provided information by kiosk may differ depending on installation environment. Namely, the information and users differ by the features of spaces such as characteristics, roles, functions and etc, then the relevant contents should be composed differently. In addition, information-delivering kiosk in public spots doesn't have any obvious users, so it should be easier and convenient for anyone who wants to access, operate and use so that nobody feels alienated. It could be measurable by popularity from kiosk UX factors's study results.

The above study results can be used effectively for evaluating and improving digital kiosk which is installed all over the city and is providing various information. Further, it would be very useful for the next development or guidelines for future public information kiosk installation. It is going to reduce different types of trial and error in process of planning a new information technology. We expect that this study will contribute to expanding multimedia kiosk and could be applied as a useful tool in academic and practical aspects.

Moreover, this study suggested more significant information through big data than the existing offline's data, and provided guidelines for how big data can be used when it comes to UX research in respect of offering rapidly-changing current problems or issues right away.

Yet this study had the following limitations. First, it was insufficient to study the preceding research about analysis on big data, and there were less unity and completion in respect of material's forms and contents from social media. Second, the key words were selected with less validity when using a big data analysis tool. Because the utilization of an analysis tool was pretty low so that it could be hard for study results to generalize.

\section{Acknowledgments}

Funding for this paper was provided by Namseoul University.

This paper is a revised and expanded version of a paper entitled Elements of user experience of kiosks in public places presented at HSST, Daejeon, Korea, December 21232017.

\section{References}

[1] H.-J. Sung, H.-R. Woo and Y.-J. Ko, "Characteristics of information kiosk from universal design perspective-focused on the case study of existing kiosk", Proceedings of Archives of Design Research, Seoul, Korea, Spring, (2007), pp. 18-19.

[2] J.-W. Won, "A study of applying experience elements to digital contents of public service design: based on the composition of information contents for kiosks", Hanyang University, Seoul, (2011).

[3] E.C. Edwards and D.J. Kasik, "User experience with the cyber graphics terminal", Proceedings of VIM21, Denver, USA, (1974), pp. 284-286.

[4] N. Donald, "The Design of everyday things", Basic Books, New York, (1988)

[5] B.-W. Shin and J.-H. Lee, "Inside community", Ahn Graphics, Seoul, (2006).

[6] J. J. Garrett, "The Elements of user experience: User-Centered Design for the Web and Beyond", Pearson Education, USA, (2010).

[7] J.A. Russell, J.A. Bachorowski and J.M. Fernandez-Dols, "Facial and vocal expressions of emotion", Annual Review of Psychology, vol. 54, (2003), pp. 329-349.

[8] P. Morville, "User experience honeycomb", URL: http://www. pearltrees. com/marleybarley/tree/id7610835/pearl72914315, (2006). 
[9] M. Hiltunen, M. Laukka and J. Luomala, "Mobile user experience", IT Press, Finland, (2002).

[10] M. Hassenzahl and N. Tractinsky, "User experience: a research agenda", Behavior \& Information Technology, vol. 25, no. 2, (2006), pp. 91-97.

[11] A.-K. Pietiläinen, E. Oliver, J. LeBrun, G. Varghese and C. Diot, "MobiClique: Middleware for mobile social networking", Proceedings of the 2nd ACM workshop, Barcelona, Spain, (2009), pp. 49-54.

\section{Author}

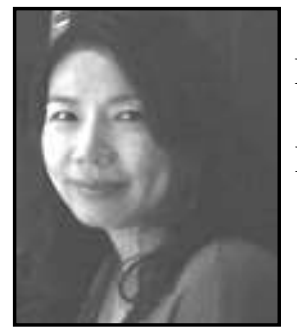

Seungmin Lee, she received the M.A. and Ph.D. degree in Image Media from Ewha Womans University in 2000 and 2011 respectively. She is currently an assistant professor in NamSeoul University. Her research interests include multimedia contents. 